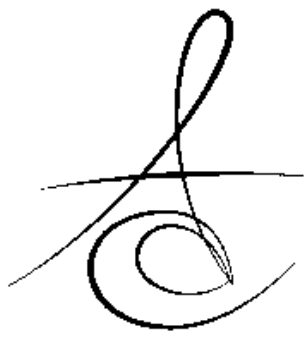

Makale Kodu/Article code: 1433

Makale Gönderilme tarihi: 09.12.2013

Kabul Tarihi: 12.03.2014

\section{POLİETİLEN FİBER DESTEKLİ ADEZIV KÖPRÜ UYGULAMALARI (ÜÇ OLGU SUNUMU)}

\section{ADHESIVE BRIDGE APPLICATION REINFORCED POLYETHYLENE FIBER (REPORT OF THREE CASES)}

Arş. Gör. Dt. Mehmet ADIGÜZEL

Arş. Gör. Dt. Mehmet Gökhan TEKİN

Yrd. Doç. Dr. Zeki ARSLANOĞLU

\section{ÖZET}

Günümüzde anterior bölgedeki diş eksikliklerinde, hastalar hızlı bir şekilde estetik bir görünüme sahip olmayı isteyebilmektedir. Fiberle güçlendirilmiş adeziv köprüler, hastaların estetik ihtiyaçlarının karşılanması gerektiğinde iyi bir alternatif tedavi yöntemi sağlayabilmektedir. Bu sistemlerin estetik ve konservatif olarak tedavi edilebilmesi bu konudaki yöntemlerin hastalar ve hekimler tarafından ilgi görmesini sağlamıştır. Bu alternatif tedavi; periodontal açıdan sorun oluşturan destek dişlerin varlığında, travma sonucu oluşan diş kayıplarında ve implant tedavisi sırasında yükleme öncesi geçici restorasyon yapımında uygulanabilir. Bu tip köprülerin; destek dişlerde minimum hasar oluşturması, tedavi süresini kısaltması, diğer tekniklere göre daha ucuz olması ve istenmeyen durumlarda geri dönüş imkanını verebilmesi gibi bir takım avantajları bulunmaktadır. Bu makalede, polietilen fiber destekli adeziv köprü uygulamaları ve takipleri sunulmaktadır.

Anahtar Kelimeler: Polietilen fiber destekli adeziv köprü, estetik - konservatif tedavi

\section{ABSTRACT}

Nowadays, patients quickly can want to have an aesthetically pleasing appearance due to lack of teeth on the anterior region. Fiber reinforced adhesive bridges can provide a good alternative treatment method when they ensure aesthetic requirements of patients. These systems can be treated as the aesthetic and conservative methods has led to the interest by patients and doctors in this field. This alternative treatment is practise that can be applied for presence of supporting teeth with periodontal disease and lossing teeth result from tauma and production temporary restoration before installation during implant treatment. There are a number of advantages of this type of dental bridge such as being minimal damage on support teeth, shortening the duration of treatment, being cheaper compared to other techniques and providing possibility of return back when unwanted situations. In this article, polyethylene fibers adhesive-backed bridge application and follow-up are presented.

Keywords: Polyethylene fiber-reinforced adhesive bridges, aesthetic- conservative treatment

\section{GİRİŞ}

Son yıllarda adeziv diş hekimliğindeki olumlu gelişmeler ile birlikte adeziv köprüler, tek diş eksikliklerinde uygulanabilecek tedavi alternatifleri arasında yerini almıştır. ${ }^{1}$ Tek diş eksikliğinin tedavisinde genel olarak sabit protez veya implant üstü kron seçenekleri düşünülmektedir. Ancak geleneksel sabit protezlerin, boşluğun her iki yanındaki dişlerin kesimini gerektirmesi ve seans sayısının çok olması gibi çeşitli zorlukları bulunmaktadır. Dental implant tedavileri de mevcut sistemler içinde oldukça başarılı olmasına rağmen tedavinin yüksek maliyetli olması, iyi bir ağız hijyeni gerektirmesi, metal alerjisi olan hastalarda kontrendike olması, ileri cerrahi operasyon gerektirmesi ve implant cerrahisinden sonra implant üstü restorasyon yapılana kadar en az 3 ay osseointegrasyon için beklenilmesi gibi dezavantajları bulunmaktadır. ${ }^{2-5}$ Günümüzde bu tip köprüler tek diş eksikliklerinin restorasyonunda sıklıkla kulla-

*Mustafa Kemal Üniversitesi, Diş Hekimliği Fakültesi, Endodonti A.D,

**Mustafa Kemal Üniversitesi, Diş Hekimliği Fakültesi, Restoratif Diş Tedavisi A.D

***Mustafa Kemal Üniversitesi, Diş Hekimliği Fakültesi, Pedodonti A.D, 
Atatürk Üniv. Diş Hek. Fak. Derg.

] Dent Fac Atatürk Uni

Supplement: 10, Yll: 2015, Sayfa : 30-36
ADIGÜZEL, TEKİN, ARSLANOĞLU nılmakta ve diş hekimliğinde standart işlemler arasında sayılmaktadır. 6,7

Ribbond (Ribbond; Inc., Seattle, WA, USA) yüksek elastik modüle sahip, yüksek moleküler ağırlıklı polietilen fiber içerikli ve mekanik olarak iyi özelliklere sahip şerit şeklinde bir materyaldir. Bu materyalin özel fiber ağ yapısı, kaviteye daha iyi uyum sağlanmasını ve bütün yönlerde elastisite modülü ve ısısal genleşme katsayılarının daha dengeli olmasını sağlar. ${ }^{8}$ Metal içermeyen bir materyal olup translüsens, şeffaf, inert ve biyouyumlu bir yapıya sahiptir. ${ }^{9}$ Kompozitlerle kombine kullanımı estetik açıdan tatminkar sonuçlar sağlayabilmektedir. Bu materyal C faktörünün artmış olduğu endodontik tedavi edilmiş dişlerin güçlendirilmesinde, periodontal splintlemede, avulse dişlerin splintlenmesinde, protez tamirinde, ortodontik tedavilerde, geçici veya daimi köprü yapımında kullanılabilmektedir. ${ }^{10}$

Fiberle güçlendirilmiş adeziv köprülerin uygulanması esnasında gövde kısmı hastanın kendi dişinden veya kompozit rezinden hazırlanarak uygulanabilmektedir. ${ }^{6}$ Bu makalede, köprü gövdesinin biri hastanın kendi dişinden, diğer ikisi de kompozit rezinden oluşturulan polietilen fiberle yapılmış olgu sunumları anlatılacaktır.

\section{OLGU SUNUMU 1}

42 yaşındaki erkek hasta 7 yıl önce yaptırmış olduğu adeziv köprünün düşmesi şikâyetiyle kliniğimize başvurmuştur. Alınan anamnezde adeziv köprünün travma sonucu düştüğü ve düşmeden önceki süreçten hem estetik hem de fonksiyonel açıdan memnun olduğu öğrenilmiştir. Yapılan ağız içi muayenede köprünün tamirinin mümkün olmadığı ve yeniden restorasyon yapılması gerektiği görülmüştür. Hastaya yeniden adeziv köprü restorasyonu planlanmış ve polietilen fiber (Ribbond, Seattle, WA, USA) kullanılarak adeziv köprü yapımına karar verilmiştir. Destek dişlerin üzerindeki eklentiler uzaklaştırılmış ve maksiller sol santral ile kanin dişlerin bukkal ve lingual mine yüzeylerine bizotaj yapılmıştır. Dentinde damla şeklinde oluklar açılmıştır. Dişlerin palatinal orta üçlüsüne $0,5 \mathrm{~mm}$ derinliğinde ve kullanılacak ribbond kalınlığında (yaklaşık $2.5 \mathrm{~mm}$ ) oluklar açılmıştır. Prepare edilen mine ve dentin yüzeyine \% 37'lik fosforik asit uygulandıktan sonra dişler yıkanıp kurutulmuştur. Sonrasında yüzeylere dentin bonding ajanı (Clearfil SE bond, Kuraray, Osaka, Japan) uygulanarak 15 sn ışık ile polimerize edilmiştir. Bonding işlemi yapılan yüzeylere akışkan kompozit rezin, (GrandioFlow, VOCO, Cuxhaven, Germany) ince bir tabaka seklinde uygulanıp ribbond yerleştirilmiştir. Ribbond: santral diş orta $1 / 3$, lateral diş, kanin diş orta 1/3 ünü kapatacak uzunlukta ark biçiminde olacağı düşünülerek hazırlanmıştır. Ayrıca, bond ile ıslatılıp ışık görmeyecek şekilde bekletilmiş ve polimerize edilmemiş akışkan kompozit üzerine yerleştirilmiştir. Ribbond'un yüzeye adaptasyonu ince uçlu bir amalgam fulvarı ile sağlandıktan sonra 20 sn boyunca ışıkla sertleştirilmiştir. Uyumlaması yapılan kompozit rezin gövdenin lingual yüzeyine ribbond kalınlığında ve dental arka oturacak şekilde oluk açılmış ve asit uygulamasını takiben ince bir tabaka akışkan kompozit uygulanmıştır. Daha sonra gövde Ribbond üzerine adapte edilip 20 sn boyunca ışık uygulanarak polimerize edilmiştir. Son olarak Ribbond'un açıkta kalan kısımları nanohibrit kompozit rezin (Grandio, VOCO, Cuxhaven, Germany) ile kapatılarak polimerize edilmiştir. Bitirme diskleri ( Sof-lex,3M ESPE, USA), bitirme frezleri (extra fine) ve polisaj lastikleri ile yüzey düzgünlüğü sağlanmıştır. Hastanın 12 aylık takibinde periodontal olarak sağlıklı görünümde olduğu, restorasyon bölgesinde hafif renklenmelerin, kırılma ve çatlamaların olduğu görülmüştür. (Resim $1 a, b, c, d, e)$

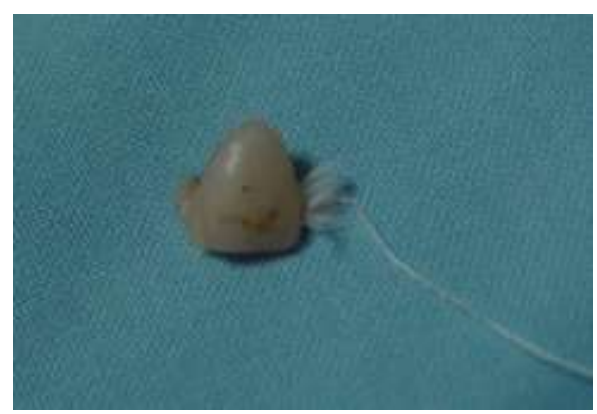

Resim 1a. 7 yı önce yapılmış fiber destekli rezin kompozit

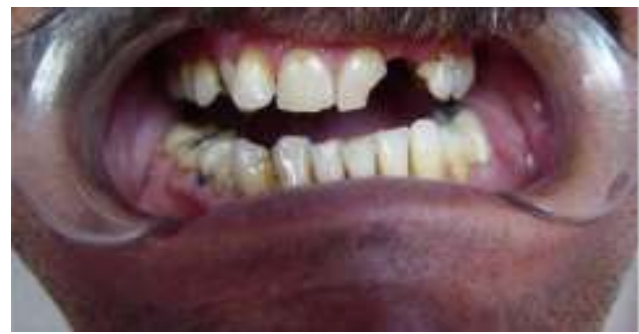

Resim 1b. Tedavi öncesi ağız içi görünüm 
Atatürk Üniv. Diş Hek. Fak. Derg.

J Dent Fac Atatürk Uni

Supplement: 10, Yll: 2015, Sayfa : 30-36

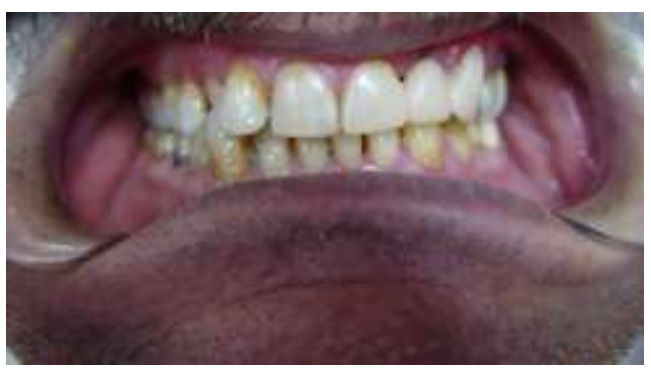

Resim 1c. Tedavi sonrası bukkal görünüm

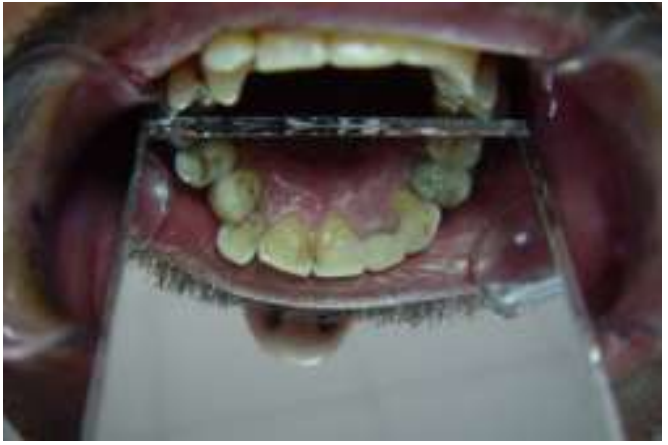

Resim 1d. Tedavi sonrası lingual görünüm

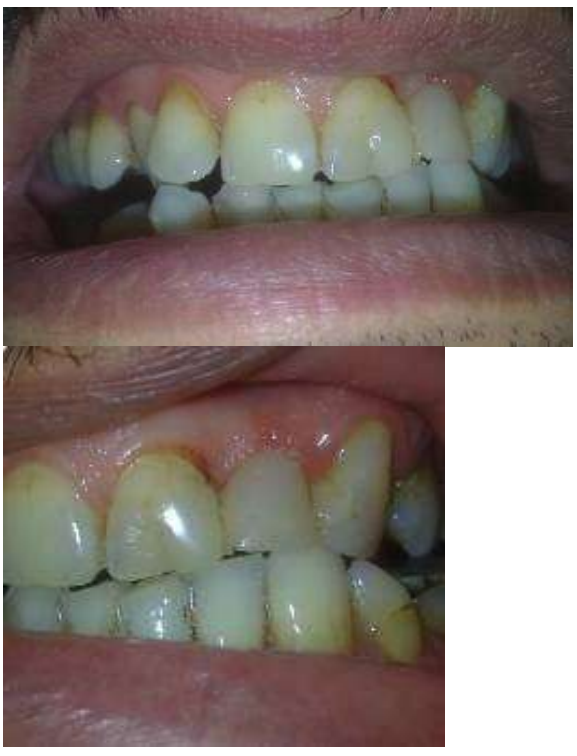

Resim 1e. 12 ay sonraki ağız içi görünüm

\section{OLGU SUNUMU 2}

Sosyo-ekonomik yetersizlik nedeniyle ortodontik tedaviye imkanı bulunmayan 20 yaşındaki bayan hasta
ADIGÜZEL, TEKİN, ARSLANOĞLU

kliniğimize başvurmuştur.Hastanın yapılan ağız içi muayenesinde, çapraşık sol üst lateral ve komşu dişlerin sağlıklı olduğu gözlenmiştir. Radyografik muayenede, ilgili bölgede herhangi bir patolojik durum izlenmemiştir. Komşu dişlerin aproksimal yüzeyi ve çapraşık keser dişin labial yüzeyine asit ve bonding uygulamaları yapıldıktan sonra akışkan kompozit rezin (GrandioFlow, VOCO, Cuxhaven, Germany) ince bir tabaka şeklinde uygulanıp polimerize edilmeden bekletilmiştir. Santral ve kanin dişe yüzeyel temas edecek şekilde hazırlanan bond emdirilmiş fiber şerit, polimerize edilmemiş akışkan kompozit üzerine yerleştirildi. Kondense edilip, 20 sn boyunca ışıkla sertleştirilmiştir. Fiber şerit üzerinde, nanohibrit kompozit rezin (Grandio, VOCO, Cuxhaven, Germany) ile lateral diş formu verilen gövde oluşturulup polimerize edilmiştir. Bitirme diskleriyle ( Sof-lex,3M ESPE, USA) kompozit yüzeyleri düzeltildi ve polisaj işlemi gerçekleştirildi. Hastanın 12 aylık takibinde renklenme ve kırılma olmadığı, komşu dişetinde hafif enflamasyon olduğu görülmüştür. Hastanın yapılan restorasyondan herhangi bir şikayetinin olmadığı belirtilmiştir. (Resim 2a,b,c)

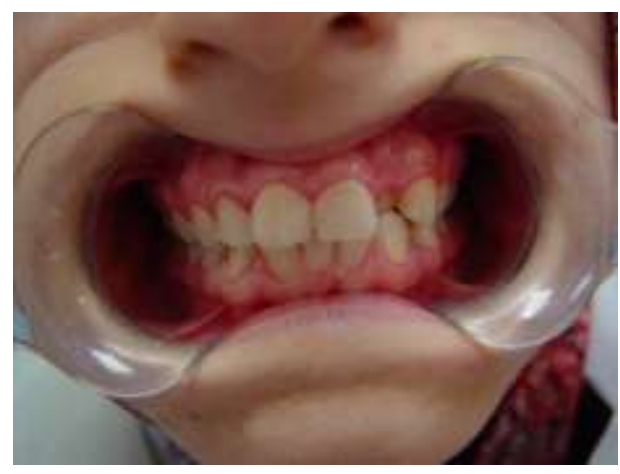

Resim 2a. Tedavi öncesi ağız içi görünüm

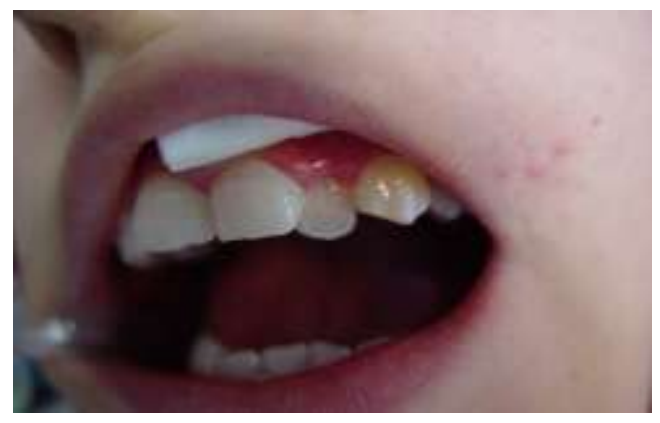

Resim 2b. Polietilen fiberin uygulanması 
Atatürk Üniv. Diş Hek. Fak. Derg.

J Dent Fac Atatürk Uni

Supplement: 10, YIl: 2015, Sayfa : 30-36

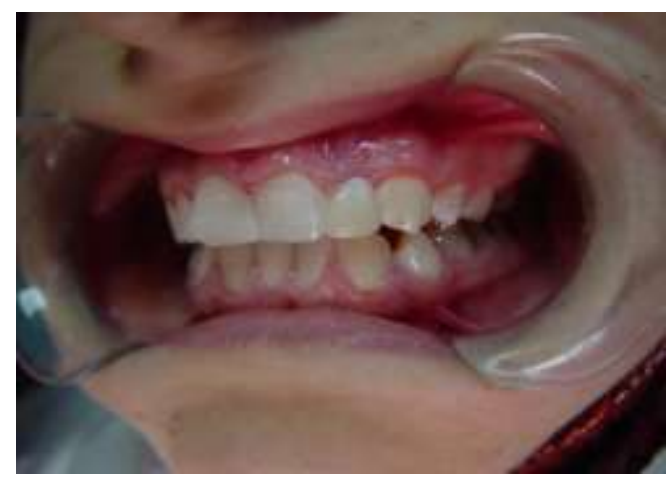

Resim 2c. Tedavi sonrası ağız içi görünüm

\section{OLGU SUNUMU 3}

48 yaşında bayan hasta periodontal hastalık sebebiyle çekimi planlanlanmış sağ alt santral dişin tedavisi için kliniğimize başvurmuştur. Hastanın yapılan ağız içi muayenesinde alveolar krette rezorpsiyon olduğu ve komşu santral dişinde de alveolar kemik kaybı, dişeti çekilmesi ve mobilite olduğu gözlenmiştir. Sağ alt santral dişin çekimi yapılmış ve çekilen diş hasta tarafından muhafaza edilip, sonrasında dişin alveol krete göre uyumlaması yapılmıştır. Dişin apikal kısmından pulpa odası boşaltılmış ve akışkan kompozitle doldurulmuştur. Pulpa odası doldurulan dişten adeziv köprü için bir gövde oluşturulmuştur. Kanin dişlerin orta $1 / 3$ okluzale yakın birbirine bakan bölgelerine $0,5 \mathrm{~mm}$ derinliğinde, yaklaşık $2,5 \mathrm{~mm}$ kalınlığında oluklar açılmıştır. Arada kalan dişlere de aproksimal ve lingual yüzeylerinin orta $1 / 3$ bölümlerine oluklar hazırlanmıştır. Hazırlanan dişlerde akışkan kompozitin taşmamasını ve plak retansiyonunu önlemek amacıyla dişlerin arasına lingualden kamalar yerleştirilmiştir Asit ve bonding uygulamaları yapılmıştır. Bonding uygulanmış yüzeylere akışkan kompozit rezin (Filtek $^{\text {TM }}$ Supreme XT, 3M ESPE, St. Paul, MN, USA) ince bir tabaka şeklinde uygulanıp polimerize edilmeden bekletilmiştir. Bond emdirilmiş fiber şerit, polimerize edilmemiş akışkan kompozit üzerine yerleştirilmiş olup 20 sn boyunca ışıkla sertleştirilmiştir. Uyumlaması yapılan gövdenin lingual yüzeyine asit ve bonding uygulamasını takiben ince bir tabaka akışkan kompozit uygulanmıştır. Daha sonra gövde fiber şerit üzerine adapte edilip tekrar 20 sn boyunca polimerize edilmiştir. Son olarak, fiber şeritin açıkta kalan kısımları nano hibrit kompozit rezin (Filtek ${ }^{\mathrm{TM}} \mathrm{Z250,3M-ESPE}$, St. Paul, MN, USA) ile kapatılarak polimerize edilmiştir.
ADIGÜZEL, TEKİN, ARSLANOĞLU

Kamalar çıkarılmıştır. Bitirme frezleri (extra fine) ve polisaj lastikleri ile yüzey düzgünlüğü sağlanmıştır. Hastanın çekilen dişi kullanılarak, estetik beklentiler en iyi şekilde karşılanmaya çalışılmıştır. (Şekil $3 a, b, c, d, e)$

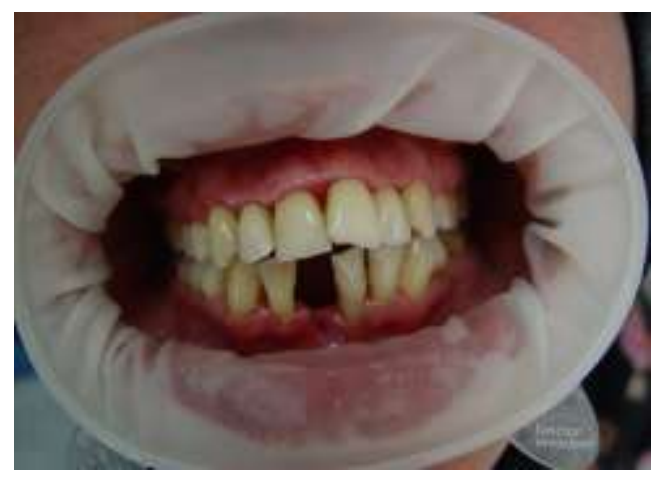

Resim 3a. Tedavi öncesi ağız içi görünüm

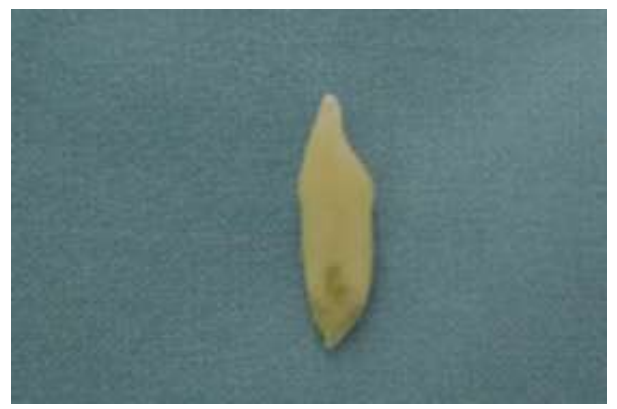

Resim 3b. Uyumlama öncesi aproksimalden görünüm

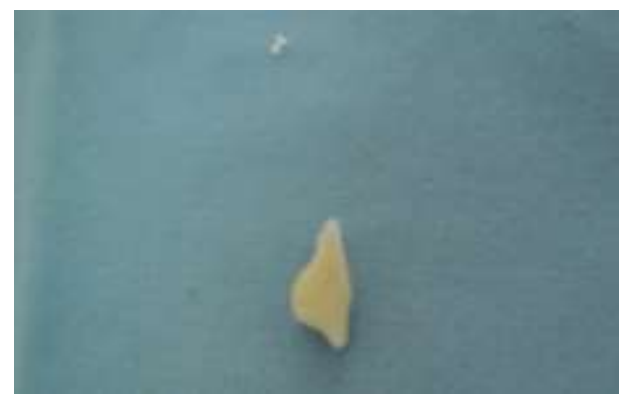

Resim 3c. Uyumlama sonrası aproksimalden görünüm 
Atatürk Üniv. Diş Hek. Fak. Derg.

J Dent Fac Atatürk Uni

Supplement: 10, Yıl: 2015, Sayfa : 30-36

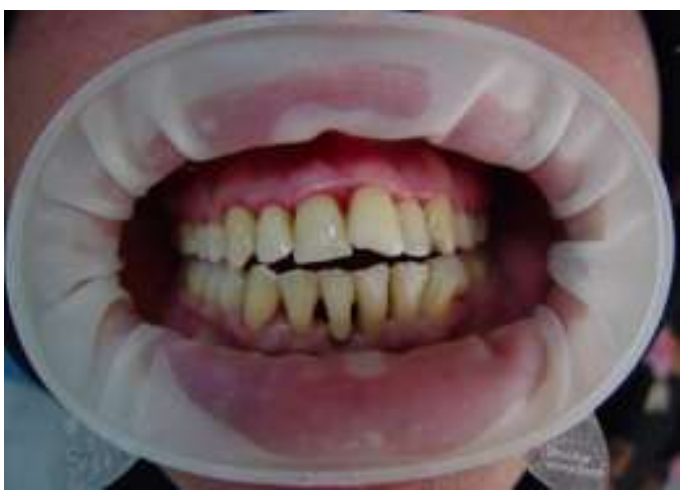

Resim 3d. Tedavi sonrası bukkal görünüm

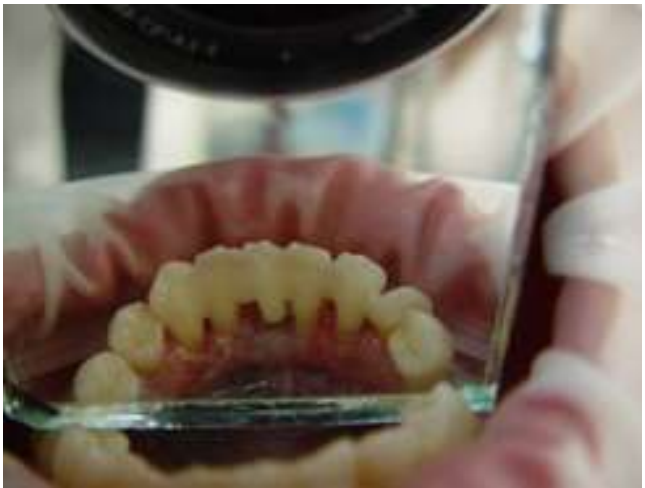

Resim 3e. Tedavi sonrası lingual görünüm

\section{TARTIŞMA}

Anterior bölgedeki diş kayıplarının tedavisinde implantlar, geleneksel köprüler, tutucu- destek elemanları ve alternatif bir tedavi olan adeziv köprüler gibi çeşitli tedavi seçenekleri kullanılmaktadır. ${ }^{11}$ Özellikle implant uygulamaları günümüzde hastalar tarafından tercih edilen başarılı bir tedavi seçeneğidir. Ancak implant destekli bir restorasyonun sağlıklı bir şekilde yapılabilmesi için implant cerrahisinden sonra implant üstü restorasyon yapılana kadar (3-6 ay) osseointegrasyon için beklenilmesi gerekmektedir. Bu süre boyunca, hastalar estetik, fonksiyon ve fonasyon açısından olumsuz olarak etkilenebilmektedir.

Diş hekimliğinde farklı fiber tipleri kullanılmaktadır ve bunların arasında en sık kullanılan tipleri, üstün mekanik ve estetik özelliklerinden dolayı polietilen ve cam fiberlerdir. Yapılan çalışmalarda, translusent özelliği, estetik oluşu ve dentine bağlanma kapasitesi nedeniyle farklı tipteki fiberler arasında dental
ADIGÜZEL, TEKİN, ARSLANOĞLU

kullanıma en uygun olanın cam fiberler olduğu gösterilmiştir. ${ }^{12}$

Polietilen fiberler, cam fiberlerle karşılaştırıldıklarında daha yüksek molekül ağırlığına, daha düşük bükülme dayanıklılığına ve daha pürüzlü bir yüzeye sahip olduğu görülmüştür. Ayrıca, polimer matrixe yeterli derecede bağlanamayabilir. Polietilen fiberler plak birikiminin en fazla görüldüğü fiberlerdir. ${ }^{13-14}$ Çalışmamızda plak birikiminin önlenmesi amacıyla polietilen fiber kompozitle kapatılmıştır. Polietilen fiber, yüksek kırılma direnci ve darbe dayanımına sahiptir. ${ }^{15}$ Cam fiberlere göre klinik uygulama daha kolaydır. Direkt yöntemde uygulama kolaylığı sağlaması açısından daha çok polietilen fiberler tercih edilmektedir. ${ }^{3}$ Restorasyonun indirekt yöntemle yapılma olasılığı bulunuyorsa dimetakrilat rezin matrix emdirilmiş cam fiberler kullanılabilmektedir. ${ }^{4}$ Cam fiberin bükülme dayanıklılığı, polietilen fiberden yaklaşık olarak 2 kat ve bükülme modülü ise 8 kat daha fazladır. Cam fiberdeki bu üstünlük veneer yapılan kompozitin bütünlüğünün korunması bakımından önemlidir. Cam fiberler diğer fiber çeşitlerine göre daha translusent materyallerdir. Bu sebeple daha estetik restorasyonlar elde edilebilir. ${ }^{5}$ Yüksek dayanıklılık, polimerlere silan kaplama materyali yoluyla yüksek bağlanma kuvveti göstermesi, diğer fiber türlerine göre plak birikim oranının daha az olması ve düşük maliyette olması cam fiberlerin diğer avantajlarındandır. ${ }^{2,4}$ Çalışmamızda direkt yöntemle uygulama kolaylığı, yüksek kırılma direnci ve darbe dayanımı, şerit şeklinde dental arka daha iyi uyum sağlaması nedeniyle polietilen fiber kullanılmıştır.

Polietilen fiber ile güçlendirilmiş adeziv köprüler özellikle implant vakalarının iyileşme sürecinde geçici olarak kullanılabilirler. Eskitaşcıoğlu ve ark. polietilen fiber destekli adeziv köprülerin implant tedavilerinde osseointegrasyon öncesi geçici amaçlı kullanımını önermişlerdir. ${ }^{16}$ Anterior bölgede tek diş eksikliği bulunan vakalarda uygulanabilen bu yöntem başlangıçta geçici bir yöntem olarak düşünülmüştür. Bununla beraber doğru seçilen vakalarda daimi restorasyon olarak da kullanılabilmektedir. ${ }^{17}$ Birinci olgumuzda hastamız fiber destekli adeziv köprüsünü yedi yıl boyunca sorunsuz bir şekilde kullanmış olması oldukça önemli bir noktadır. Bu olgumuz, adeziv köprü restorasyonlarının uygun endikasyonu olan vakalarda uzun dönemde başarılı olabileceğinin bir göstergesi olabilir.

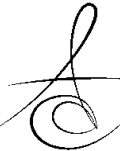


Atatürk Üniv. Diş Hek. Fak. Derg.

J Dent Fac Atatürk Uni

Supplement: 10, Yll: 2015, Sayfa : 30-36
ADIGÜZEL, TEKİN, ARSLANOĞLU
Adeziv köprü tekniği; tedavi süresini kısaltması, destek dişlerde minimum hasar oluşturması, diğer tekniklere göre daha ucuz olması, diş renginde malzemeler kullanılarak estetik sonuçlar alınması gibi bir takım avantajlara sahiptir. ${ }^{6,16}$ Ancak hassas bir çalışma gerektirmesi ve sınırlı yük taşıma kapasitesi gibi dezavantajları mevcuttur. ${ }^{18} \mathrm{Bu}$ sebeple bu tip adeziv köprülerin premolar ve molar bölgelerde kullanımları uygun değildir. Gönülol ve ark.'ları bir çalışmalarında premolar bölgeye yaptıkları adeziv köprüden başarılı bir sonuç elde edemediklerini bildirmişlerdir. ${ }^{19}$ Yaptığımız çalışmada, kuvvetlerin daha az rol oynadığı anterior bölgelerde çalışılarak, adeziv köprülerden daha başarılı sonuçlar alınması düşünülmüştür.

Kuşgöz ve ark.'ları 2 yıllık klinik takip sonunda fiberle güçlendirilmiş adeziv köprülerin kabul edilebilir bir başarısından ve hastaların tedaviyi kolayca kabullendiklerinden bahsetmişlerdir. ${ }^{20}$ Gül ve Akgül yapmış oldukları çalışmada, bir yıl ve dokuz ay boyunca farklı iki fiber destekli adeziv köprü olgusunu takip etmişlerdir. Birinci olguda sadece hastanın oral hijyene dikkat etmemesine bağlı dişeti problemi görüldüğü belirtilirken, ikinci olguda ise hastanın yapılan tedavi sonucundan oldukça memnun kaldığı bildirilmiştir. ${ }^{21}$

Uzun süren ve yüksek maliyetli tedavi prosedürlerini tolere edemeyen ve estetik beklentileri olan hastalarda adeziv köprüler ortodontik tedaviye alternatif olarak düşünülebilir. İkinci olgumuzda ortodontik tedavi endikasyonu bulunan hastada alternatif bir yol izlenerek kısa zamanda ve az bir maliyetle hastanın estetik beklentileri karşılanmaya çalışılmıştır. İleride, daha iyi sosyo-ekonomik imkanlara sahip olabilecek hastaların ortodontik tedavi seçeneğine hala sahip olduğu ve yapılan restorasyonun istenildiği zaman geri dönüşe imkan verebileceği bildirilmiştir. Bu yaklaşım uygun endikasyonu olan hastalarda anterior bölgenin geçici restorasyonunda başarıyla kullanılabilir.

Belli ve Özer, hastanın kendi dişini pontik olarak kullandıkları hastada yaptıkları bir yılık takip de estetik ve fonksiyon açısından sonuçların tatmin edici olduğunu belirtmişlerdir. ${ }^{11}$ Üçüncü olguda da hastanın kendi dişi pontik olarak kullanılarak, hastaya doğal ve estetik bir görünümle beraber fonksiyon kazandırmak amaçlanmıştır.

Bu tür adeziv köprü uygulamalarında okluzal kapanış oldukça önemlidir. Artmış overjeti bulunan vakalarda yeterli mesafe olacağından fiber köprünün uygulanacağı dişlerde oluk açılmasına gerek yoktur.
Ancak yeterli yer bulunmayan durumlarda fiber materyalin yerleştirilmesi için destek dişlerde oluk açılmalıdır. Gerekli mesafenin bulunmadığı birinci ve üçüncü olguda oluklar açılarak adeziv köprülerin retansiyonunun artırılması hedeflenmiştir.

Sonuç olarak; hasta başında tek seansta, direkt yöntemle ve özel bir işlem gerektirmeden uygulanabilen adeziv köprülerden; iyi bir tedavi planı, hassas bir çalışma prosedürü, geliştirilmiş materyaller ve hasta kooperasyonu ile uzun dönemde oldukça başarılı sonuçlar elde edilebileceği düşünülmektedir.

\section{KAYNAKLAR}

1. Kumbuloglu O, Ozdemir N, Aksoy G, User A. A different pontic design for fiber-reinforced composite bridgeworks: A clinical report. Eur J Dent 2007; 1: 50-3.

2. Garoushi S,Vallittu PK. Fiber-reinforced composites in fixed partial dentures. Libyan J Med 2006; AOP060802: 1-6.

3. Eminkahyagil N. Fiberle güçlendirilmiş kompozitlerin kullanımı. Tdbd 2004; 84: 43-4.

4. Vallittu PK. Survival rates of resin-bonded, glass fiber-reinforced composite fixed partial dentures with a mean follow-up of 42 months: A pilot study. J prosthet dent 2004; 91: 241-6.

5. Rosentiel SF, Land MF, Fujimoto J. Fiber reinforced composite fixed prostheses. In: Contemporary Fixed Prosthodontics. Ed. Dolan J. 4th ed. Elsevier Mosby; St.Louis, Miss: 2006. p. 830-40.

6. Unlu N, Belli S. Three-year clinical evaluation of fiber-reinforced composite fixed partial dentures using prefabricated pontics. J Adhes 2006; 8: 1838.

7. İlday NÖ, Zorba YO. Fiberle güçlendirilmiş kompozit ınlay köprü uygulamaları. Türkiye Klinikleri Diş Hekimliği Bilimleri Dergisi 2009; 15: 53-8.

8. ARI H., BELLİ S. Endodontik olarak tedavi edilen dişlerde güçlendirilmiş polietilen fiber post-core uygulaması: Olgu Sunumu. Cumhuriyet Üniversitesi Dişhekimliği Fakültesi Dergisi. 1999; 2: 29-32.

9. Ellakwa $A E$, Shortall $A C$, Marquis PM. Influence of fiber type and wetting agent on the flexural properties of an indirect fiber reinforced composite. J Prosthet Dent 2002; 88: 485-90. 
10. Miller TE. A new material for periodontal splinting and orthodontic retention. Compend Cond Educ Dent 1993; 14: 800-12.

11. Belli S, Özer F. A simple method for single anterior tooth replacement. J Adhesive Dent 2000; 2: 6770.

12. Lassila LV, Tezvergil A, Lahdenperä M, Alander $P$, Shinya A, Shinya A, Vallittu PK. Evaluation of some properties of two fiber-reinforced composite materials. Acta Odontol Scand 2005; 63: 196-204.

13. Vallittu PK. Prosthodontic treatment with a glass fiber-reinforced resin-bonded fixed partial denture: A clinical report. J prosthet dent 1999; 82: 132-5.

14. Kreulen CM. Fiber-reinforced adhesive partial dentures. Ned Tijdschr Tandheelkd 2003; 110: 255-60.

15. Ellakwa $A E$, Shortall $A C$, Marquis PM. Influence of fiber type and wetting agent on the flexural properties of an indirect fiber reinforced composite. J Prosthet Dent 2002; 88: 485-90.

16. Eskitascıoglu G, Eskitascıoglu A, Belli S. Use of polyethylene ribbon to create a provisional fixed partial denture after immediate implant placement: A clinical report. J Prosthet Dent 2004; 91: 11-4.

17. Van Wijlen P. A modified technique for direct, fibre-reinforced, resin-bonded bridges: Clinical case reports. J Can Dent Assoc 2000; 66: 367-71.

18. Li W, Swain MV, Li Q, Ironside J, Steven GP. Fiber reinforced composite dental bridge Part I: experimental investigation. Biomaterials 2004; 25; 4987-93.

19. Gönülol N, Kalyoncuoğlu E, Bulucu B. Fiberle güçlendirilmiş kompozit ile adeziv köprü uygulamaları: Olgu Sunumu. Atatürk Üniv. Dis Hek. Fak. Derg 2010: 20: 43-8.

20. Kusgoz A, Sener Y, Ülker M, Yıldırım S, Koyuturk $A E$. Fiberle güçlendirilmiş kompozit ile üst keser diş eksikliğinin restorasyonu. Türk Dişhekimliği Dergisi 2007; 14: 78-82.

21. Gül P, Akgül N. Direkt fiber adeziv köprü uygulamaları: Olgu Sunumu. Atatürk Üniv. Diş Hek. Fak. Derg 2012; 22: 175-9.

\section{Yazışma Adresi}

Dr. Mehmet ADIGÜZEL

Mustafa Kemal Üniversitesi

Diş Hekimliği Fakültesi

Endodonti A.B.

HATAY

E-posta: dt.mehmetadiguzel@gmail.com 